\title{
Characteristics and potential area optimization of Oil layer A reservoir in T Oilfield
}

\author{
Junhong Gao \\ The Ninth Oil Production Plant of Daqing Oilfield Co., Ltd., Heilongjiang, China Daqing 163000 China
}

\begin{abstract}
Oil layer A of T oilfield has a low development degree. At present, there are 5 medium and highyield wells in the area, showing a good evaluation and development prospect. In order to understand the reserve potential of this area, the reservoir forming law and reservoir characteristics are further analyzed by analyzing the structure and reservoir development characteristics. The research shows that Oil layer A has two types of reservoirs: one is structural reservoir, which is distributed in the large structural trap near the Aogula-Halahai fault zone in the east of the oilfield. It is characterized by close oil source, short migration path and stable reservoir development. It is a "large and enriched" reservoir. The other type is lithologic reservoir, which is distributed at the sedimentary end of the western structure of the oilfield, and is characterized by distant oil source. After long-distance secondary migration, it is greatly influenced by the development degree and physical properties of the reservoir, but it is a "small but fat" reservoir with high oil saturation. On the basis of clarifying reservoir types, characteristics and evaluation ideas, this paper carries out reserve optimization classification, and selects three potential areas: block Y1 and block Y2 which are mainly controlled by structure and block Y3 which is controlled by lithology.
\end{abstract}

Keywords: T oil field, Oil layer A, Reservoir characteristics, Potential area optimization.

\section{Introduction}

$\mathrm{T}$ Oilfield is structurally located on two secondary structural units, Longhupao-Da'an Terrace and QijiaGulong Sag in the western part of the central depression area in the northern Songliao Basin. There are many longitudinal oil-bearing layers, from top to bottom, they are A, Saertu, Putaohua, Gaotaizi, Qing 1st Member and Fuyu oil layer. Oil layer A has the characteristics of low degree of development, shallow burial, relatively simple oil-water relationship, and high abundance of oil and gas reserves, showing good evaluation and development prospects. Previous studies mainly focused on the Sapu and Gaofu oil layers in the lower part [1-6]. Due to the sparse fracture on the top surface of Oil layer A, single formation occurrence, large difference in sand body type, scale and thickness, the scale of Oil layer A reservoir is relatively small. Therefore, previous studies on Oil layer A are relatively few, which restricts the upgrading and effective production of Oil layer A reserves in this area. In this paper, by systematically analyzing the structure and reservoir development characteristics, the reservoir forming rules and reservoir characteristics are further deeply analyzed, and then the evaluation ideas are determined. Three potential blocks of "big but rich" and "small but fat" reservoirs are found, which are used step by step according to the reservoir implementation degree. It has certain guiding significance for the exploration and development of Oil layer A of $\mathrm{T}$ oilfield and similar oilfields.

\section{Geological characteristics research}

\subsection{Structure background}

The structural pattern of the top surface of Fuyu-Oil layer $\mathrm{A}$ in the $\mathrm{T}$ oilfield is roughly the same, from deep to shallow, the overall structure is a monoclinic high in the northwest and low in the southeast. The structure is relatively flat, and the structure changes from complex to simple. The Aogula-Halahai fault zone and the Bayanchagan fault zone, which run through the entire area in the north-south direction, are developed on the monoclinic. Many local structures are formed under the background of the fault zone. These fault blocks and micro-amplitude structures are Favorable location for oil and gas accumulation [7].

The overall structure of the top surface of Oil layer A is relatively simple, and it is still a monoclinal structure. It is still the inherited development of two fault zones that control the structural pattern, but the number of associated small faults is reduced. Many structural traps are developed along the fault zone. Gulong sag is located to the east of Aogula Halahai fault zone in the East. The structural dip angle becomes larger and the structural axis 
is obvious. The formed structural traps are large, the trap amplitude is relatively large and the number is large. Three large structural traps are developed along the eastern fault zone, with an area of $0.8 \sim 3.5 \mathrm{~km} 2$ and a closing range of $20 \sim 30 \mathrm{~m}$. Bayanchagan fault in the west has a small development scale, gentle structure, few local structures and small trap amplitude and area. Two relatively large structural traps are developed, with a trap area of $0.4 \sim 0.9 \mathrm{~km} 2$ and a closure amplitude of $10-15 \mathrm{~m}$ (Figure 1).

\subsection{Sedimentary and reservoir characteristics}

Oil layer A is dominated by the delta sedimentary system in the northeast, experienced three large-scale regresses, and developed three reverse cycles. The reservoir is dominated by estuary bar and sheet sand deposits, and the predelta facies develops to the southwest. During the deposition of the A5 small layer, the T area was in the predelta-semi-deep lake subfacies. During the deposition of the A4 small layer, the delta front advanced west and south, developed delta front estuary bar and sheet sand deposits, and developed front mud microfacies at the northwestern edge of the block (Figure 2). During the deposition of the A3 small layer, the T area was in the predelta-semi-deep lacustrine facies. During the deposition period of A2 sublayer, it is in the delta front and pre delta deposition, and sheet sand bodies are developed, which are mainly distributed in the northeast and south of the block, and the front mud microfacies are mainly distributed in the northwest of the block (Figure 3). During the sedimentary period of A1 sublayer, it is in pre delta semi deep lake facies, mainly developing front mud microfacies [8]. During the evolution process of lacustrine transgression and lake regression, the distribution of the various small sedimentary facies belts controls the development range of the reservoir. The A4 and A 2 small layers are in the front subfacies of the northern delta sedimentary system, depositing estuary bars and sheet sand sand bodies, providing good storage space for Oil layer A oil and gas reservoirs in the T oilfield.

On the whole, the distribution of sandstone in Oil layer A is stable, with sandstone thickness of 2-1 4m and single sandstone thickness of $1-4 \mathrm{~m}$. Sandstone is mainly distributed in the eastern part of the work area, with thickness of 6-12m generally, and sandstone development layers are generally between 2-6 layers, of which 2-4 layers are the main ones. Sandstone is thinned along the upward dip direction of stratum, and the northwest and southwest are areas with low sandstone thickness. Vertically, sandstone is mainly developed in small layers $\mathrm{A} 2$ and $\mathrm{A} 4$. The penetration rate of small layer A2 sandstone is $63.2 \%$, and that of small layer A4 sandstone is $88.5 \%$. The average core porosity of Oil layer $\mathrm{A}$ is $20.3 \%$, and the air permeability is $61.7 \times 10-3 \mu \mathrm{m} 2$, medium porosity and medium permeability reservoir.

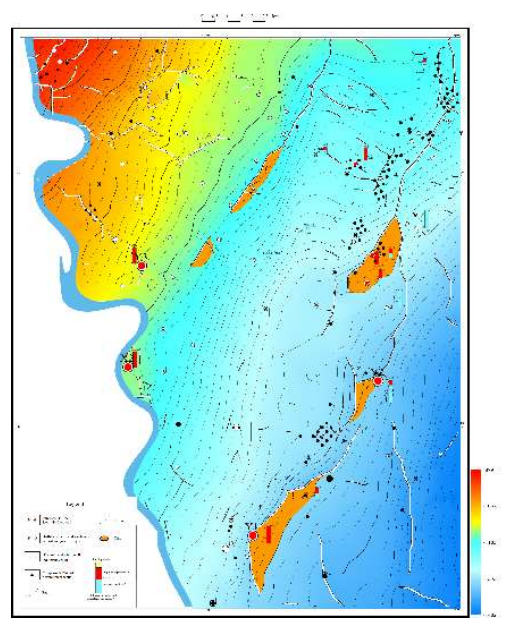

Figure 1 Oil layer A top surface structural trap diagram

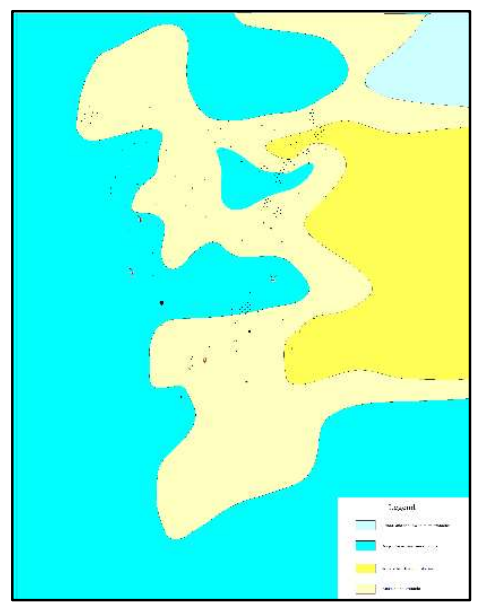

Figure 2 Plane distribution diagram of microfacies of A2 small layer deposition

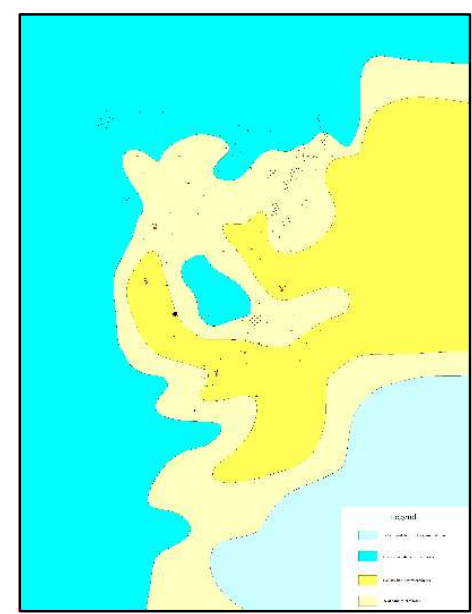

Figure 3 Plane distribution diagram of microfacies of A4 small layer deposition 


\subsection{Analysis of reservoir types, characteristics and reservoir forming laws.}

\subsubsection{Reservoir forming analysis}

$\mathrm{T}$ oilfield is adjacent to the oil-generating center of Gulong sag. The effective source rocks in the west of Daqing Placanticline are mainly distributed in QijiaGulong area, and the first member of Qingshankou Formation is the main source rock in the middle and shallow layers. The analysis of source rocks and aromatic hydrocarbon types of crude oil in A, Sarthou, Putaohua, Gaotaizi and Fuyu oil layers in $\mathrm{T}$ area shows that the crude oil in Oil layer A mainly comes from the source rocks of the first member of Qingshankou Formation.

The effective thickness of Oil layer $\mathrm{A}$ in $\mathrm{T}$ oilfield is mainly between 1 and $4 \mathrm{~m}$, mainly in the east and west. The east along the Aogula-Halahai fault zone is northsouth, distributed in a belt shape, and the effective thickness is generally between 2 and $3 \mathrm{~m}$. The western part is effectively developed at the tipping point of the sandstone or where the thickness of the sandstone becomes thinner (Figure 8). It is mainly developed in the A4 small layer, the effective drilling encounter rate of the A4 small layer is $29.9 \%$, and the effective drilling rate of the A2 small layer is $8 \%$.

The medium and high-yield wells in Oil layer A of T oilfield are mainly distributed along the Aogula Halahai fault zone in the East. It can be seen that the structure controls the reservoir. The sedimentary microfacies of Oil layer A are estuarine bar and sheet sand. Seismic reservoir prediction [9] and drilling data show that the reservoir in the east of the oilfield is developed stably. The estuarine bar and sheet sand body are blocked by faults in the structural updip direction, forming local structural traps. The monoclinic structure in the East is inclined to the oil generation center of Gulong depression, and the structural traps on it are favorable parts for oil and gas accumulation, The oil and gas generated by the lower source rock migrated to the trap along the fault zone and formed a reservoir nearby (Figure 4).

The western part of the oilfield is located in the prodelta facies, which is located at the sedimentary end in the structural updip direction. The sand body is thinned or even pointed out along the structural updip direction. The oil and gas discharged from the lower source rocks are transported to Oil layer A through faults. Because of the sparse faults on the top of the Oil layer And the single occurrence of the stratum, it is difficult to form large-scale effective structural traps. At the western end of the sedimentation, due to the influence of the sedimentary environment, the physical properties of the reservoir at the edge of the sand body become poor, and it is easy to form a lithologic oil reservoir trap (Y3 block). In the lithologic trap formed in the area where the thickness of the sandstone becomes thinner (Figure 5). However, in areas with particularly developed sand bodies, the physical properties of the reservoirs are good. Due to the multiphase activities of faults, it is easy to cause secondary migration of oil and gas, so the degree of oil and gas enrichment in the areas with particularly developed sand bodies is low or not enriched [10] .

\subsubsection{Reservoir types and characteristics}

Oil layer A reservoir types mainly include structural reservoir and lithologic reservoir. Structural reservoir has the characteristics of near oil source, short migration path and stable reservoir development. Lithologic reservoir has the characteristics of far oil source, long migration path, great influence by reservoir development and physical properties, but high oil saturation.

The structural trap formed in the Aogula-Halahai fault zone in the east is a favorable place for oil and gas accumulation. The high part of the structure in the trap produces pure oil, which transits to the low part to be the same layer of oil and water and the reservoir type is structural reservoir (Figure 6). This type of reservoir is close to the oil-generating center of the Gulong sag, with a large structural dip and an obvious structural axis. The formed structural traps are relatively large, and the range of the traps is relatively large. The fault zone provides channels for oil and gas migration and a large-area developed estuary. Dams and sheet-shaped sand bodies provide storage space for oil and gas. The oil test and production test proved that the reservoirs in this area have strong liquid supply capacity, large liquid supply radius, and a long distance from the oil-water transition zone. It is a large and enriched oil reservoir.

The sand body in the west is thinned and even pinched out along the structural updip direction. The high part of the structure in the sandstone updip direction produces pure oil, and the oil-water layer transits to the water layer from the same oil-water layer to the low part. The reservoir type is lithologic reservoir (Figure 7). There is no relatively large fault zone at the edge of this kind of reservoir to provide a channel for oil and gas migration. After the oil and gas are primarily migrated to Oil layer A through far large faults, they will undergo long-distance secondary migration and be stored in lithologic reservoir traps due to the deterioration of reservoir physical properties due to the influence of sedimentary environment. Therefore, the reservoir scale is relatively small. However, oil test proves that this kind of reservoir is a small and fat dessert reservoir with strong liquid supply capacity and large liquid supply radius. 


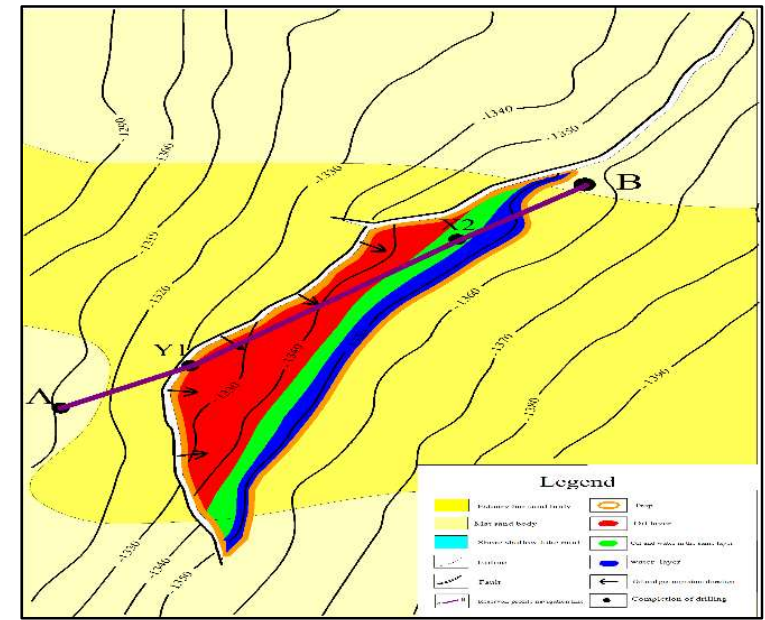

Figure 4 Structural oil reservoir formation model diagram

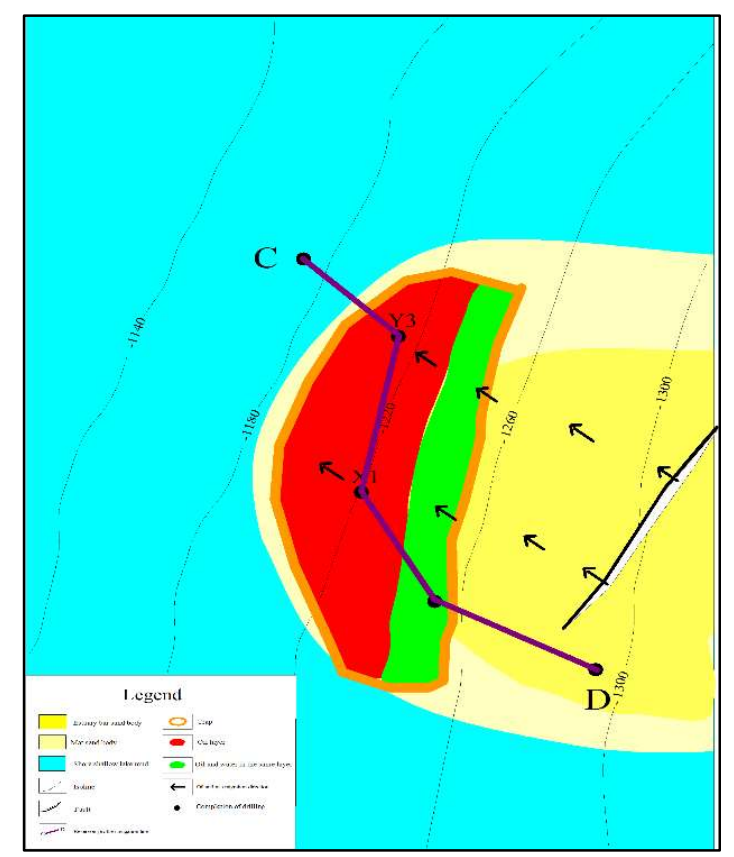

Figure 5 Lithological oil reservoir formation model diagram

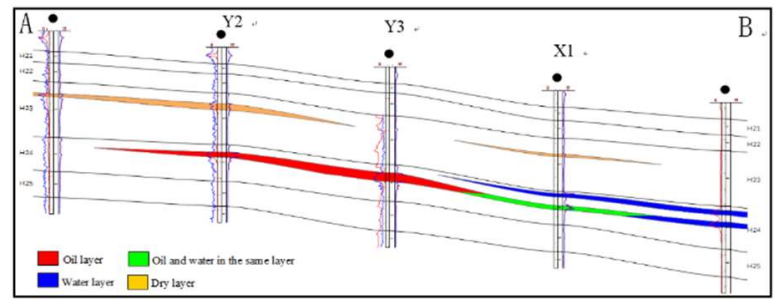

Figure 6 Oil layer A typical structural oil reservoir profile (AB)

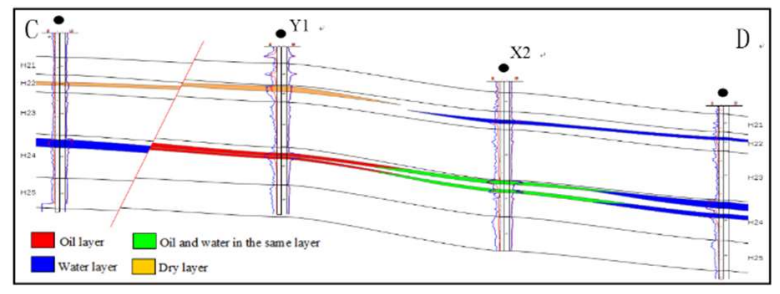

Figure 7 Oil layer A typical lithological reservoir profile (CD)

\section{Evaluation ideas and optimization of potential areas}

\subsection{Evaluation ideas}

According to the geological understanding of Oil layer A in the T oilfield, the evaluation ideas are determined: First, look for structural oil reservoirs formed by structural traps near the eastern Aogula-Halahai fault zone. The second is to look for lithologic oil reservoirs formed in the sandstone updip pinch-out or sandstone thinning area near the Bayanchagan fault zone in the west. Based on this, the potential area is optimized, the potential area is classified according to the degree of well control, the certainty of oil-water interface and the degree of reservoir implementation, and step-by-step production is considered. The block with confirmed reservoir reserves is class I area, and development wells are directly deployed. The block with low degree of reservoir implementation is class II area. Evaluation wells are deployed to further implement the reserve scale.

\subsection{Potential area optimization}

According to the above evaluation ideas, three potential blocks of Oil layer A are selected: the structural high part with large structural traps developed along the eastern fault zone, blocks Y1 and Y2 with good reservoir physical properties, and block Y3 controlled by lithology in the west (Figure 8). According to the development scale of the reservoir, the degree of well control, the physical properties of the reservoir, the thickness of the reservoir, and the oil test production, the potential areas of well deployment are classified (Table 1).

Block Y1 is located in the structural trap of Aogula Halahai fault zone, with a trap area of $3.5 \mathrm{~km} 2$ and a closure amplitude of $30 \mathrm{~m}$. After drilling, it is confirmed that the thickness of sand body is large, and the oil test production and well control degree are high. Well Y1 in the high part of the structure produces pure oil, and well $\mathrm{X} 2$ in the low part of the structure produces oil and water together. The oil-water boundary is determined. It is a class I area, and development and production is given priority.

Block Y2 is located in a small structural trap in the Aogula-Halahai fault zone, with a trap area of $0.21 \mathrm{~km} 2$ and a closure range of $5 \mathrm{~m}$. There is no well control in the trap. Well Y2 in the lower part of the trap is tested for oil. It is a water-bearing industrial oil layer. Because the trap is located in the high part of the structure and the reservoir has good physical properties, it is a favorable structural control potential area, but There is no well control in the trap, so it is determined to be a Class II area. Deploy evaluation wells in the high part of the structure to further realize the reserve potential.

Y3 block is a lithologic reservoir in the western sandstone updip pinchout area. Although the oil production of exploration and evaluation wells is relatively high, it is a Class II area due to its thin sandstone and low degree of well control. The evaluation wells are deployed in the 
structure of this area to further confirm the lithologic pinchout zone.

Table 1 Reserve potential classification table of Oil layer A in T oilfield

\begin{tabular}{|c|c|c|c|c|c|c|c|c|}
\hline $\begin{array}{c}\text { Pot } \\
\text { enti } \\
\text { al } \\
\text { blo } \\
\text { ck }\end{array}$ & $\begin{array}{c}\text { Res } \\
\text { ervo } \\
\text { ir } \\
\text { type }\end{array}$ & $\begin{array}{l}\text { Posi } \\
\text { tion }\end{array}$ & $\begin{array}{l}\text { Tr } \\
\text { ap } \\
\text { ar } \\
\text { ea } \\
(\mathrm{k} \\
\mathrm{m} \\
2) \\
\end{array}$ & $\begin{array}{l}\text { Struct } \\
\text { ure } \\
\text { amplit } \\
\text { ude } \\
\text { (m) }\end{array}$ & $\begin{array}{c}\text { Main } \\
\text { layer } \\
\text { sandsto } \\
\text { ne/effec } \\
\text { tive } \\
\text { thicknes } \\
\text { s (m) } \\
\end{array}$ & $\begin{array}{l}\text { Te } \\
\text { st } \\
\text { oil } \\
\text { ou } \\
\text { tp } \\
\text { ut } \\
\text { (t) }\end{array}$ & $\begin{array}{c}\text { Oil- } \\
\text { water } \\
\text { bound } \\
\text { ary }\end{array}$ & $\begin{array}{l}\text { Res } \\
\text { erv } \\
\text { es } \\
\text { Cat } \\
\text { ego } \\
\text { ry }\end{array}$ \\
\hline Y1 & $\begin{array}{c}\text { Stru } \\
\text { ctur } \\
\text { al } \\
\text { rese } \\
\text { rvoi } \\
\text { r }\end{array}$ & $\begin{array}{c}\text { Aog } \\
\text { ula- } \\
\text { Hal } \\
\text { ahai } \\
\text { faul } \\
t \\
\text { zon } \\
\text { e } \\
\text { Aog }\end{array}$ & 3.5 & 30 & $3.6 / 2.2$ & $\begin{array}{c}12.4 \\
8\end{array}$ & $\begin{array}{c}\text { Det } \\
\text { ermi } \\
\text { ne }\end{array}$ & $\begin{array}{l}\text { Typ } \\
\text { e I }\end{array}$ \\
\hline Y2 & $\begin{array}{c}\text { Stru } \\
\text { ctur } \\
\text { al } \\
\text { rese } \\
\text { rvoi } \\
\text { r }\end{array}$ & $\begin{array}{c}\text { Hal } \\
\text { ahai } \\
\text { faul } \\
t \\
\text { zon }\end{array}$ & 0.25 & 5 & $\begin{array}{c}\text { No well } \\
\text { control }\end{array}$ & / & $\begin{array}{c}\text { Unc } \\
\text { ertai } \\
n\end{array}$ & $\begin{array}{l}\text { Typ } \\
\text { e II }\end{array}$ \\
\hline Y3 & $\begin{array}{c}\text { Lith } \\
\text { olog } \\
\text { ic } \\
\text { rese } \\
\text { rvoi } \\
r\end{array}$ & $\begin{array}{l}\text { Upd } \\
\text { ip } \\
\text { pinc } \\
\text { h- } \\
\text { out } \\
\text { zon } \\
\text { e of } \\
\text { wes } \\
\text { tern } \\
\text { san } \\
\text { dsto } \\
\text { ne }\end{array}$ & I & / & $3.4 / 1.8$ & 8.4 & I & $\begin{array}{l}\text { Typ } \\
\text { e II }\end{array}$ \\
\hline
\end{tabular}

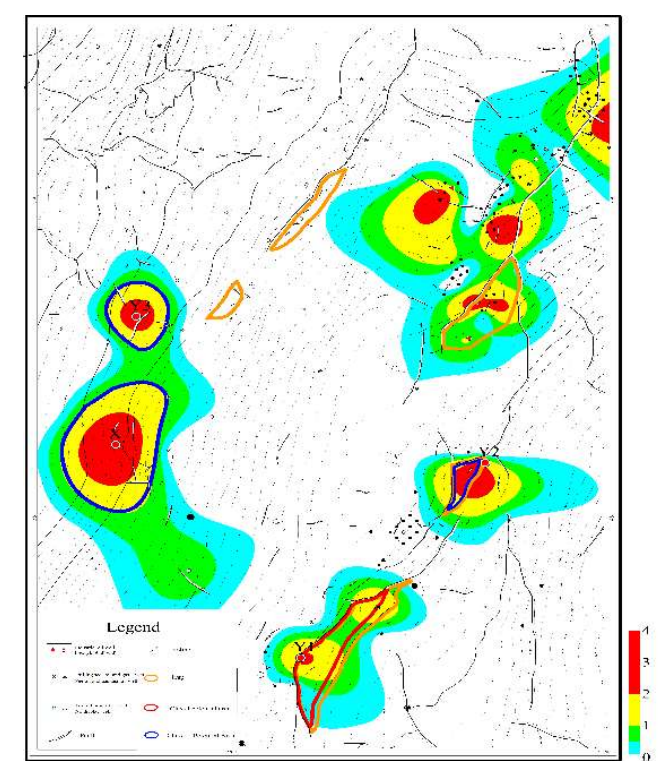

Figure 8 Effective thickness and reserves evaluation diagram of Oil layer A

\section{Conclusions}

The Oil layer A reservoir of T oilfield is mainly deposited by delta front estuary bar and sheet sand. The oil layer is mainly developed in the A4 small layer. The eastern part is controlled by structure and the west is controlled by lithology.

Oil layer A reservoir types are structural reservoir and lithologic reservoir. Structural morphology and reservoir development control the distribution and enrichment of oil and gas. The "large and rich" structural reservoir is distributed near the Aogula Halahai fault zone in the east of the oilfield, and the "small and fat" reservoir is distributed in the updip pinch out of the sandstone in the West and the small circle near the fault zone.

The structural reservoir in the east is close to the oilgenerating center of the most important hydrocarbongenerating depression in Songliao Basin, which is rich in oil source supply. The Aogula-Halahai fault zone communicates with the source rocks, providing a channel for oil and gas migration, and forming a large structural trap to provide storage space for oil and gas, so the oil and gas are accumulated nearby, so the reservoir scale is relatively large.

The lithologic oil reservoirs in the west are located at the end of structurally up-dip deposition. Because there is no relatively large fault zone at the edge of the reservoir to provide channels for oil and gas migration, oil and gas can migrate through long distances and be stored in high parts of the structure due to storage. The deterioration of layer physical properties forms lithologic reservoir traps, and the reservoir scale is relatively small.

According to the above research, Y1 and Y2 blocks near the eastern fault zone and Y3 block at the updip pinch out of sandstone in the West are preferred, which are divided into two types according to their different characteristics for step-by-step production.

\section{References}

1. Li Yihe. Study on hydrocarbon accumulation regularity and target optimization of Putaohua oil reservoir in Talaha syncline [D]. Northeast Petroleum University, 2017: 75-96.

2. Liu Gang. Stratigraphic sequence and sedimentary facies of Putaohua, Gaotaizi and Fuyu oil in TalahaQijia area [D]. Zhejiang University, 2018: 65-72.

3. Liu Xin. Study on hydrocarbon accumulation regularity of $\mathrm{Pu}$ taohua oil reservoir in Talaha-Changjiaweizi area [D]. Northeast Petroleum University, 2013: 46-69.

4. Yang Yufang, Zhong Jianhua. Re-understanding of the sedimentary and accumulation characteristics of the first member of Yao formation in The Aigujia area of Taraha, northern Songliao Basin [J] . Modern geology, 2010: 301-305 .

5. Xu Chengwu. Study on reservoir geology of Salao oil layer in Talaha area, northern Songliao Basin [D].Daqing Petroleum Institute, 2004:54-58 .

6. Lian Xiaoliang . Study on reservoir sedimentology of Putaohua oil layer in Changjiaweizi area, Talaha [D] . Jilin University, 2007:43-45

7. Ji Qingsheng,Han Ling. New Proved Oil Reserves Report in Block Y, T Oilfield[R]. 2006: 13-16 
8. Ma Fujian. Study on fine stratification of Heidi Miao oil layer in Telaha-Yingtai-Da 'an area, northern Songliao Basin [D]. Daqing Petroleum Institute, 2003:24-26

9. Liu Yuanji.Study on reservoir comprehensive evaluation inTarahasi area,Daqing[D].Zhejiang University, 2011:52-60

10. Yao Zhongwen,Wan Shuangshuang. Accumulation mechanism of Aogula-Talaha fault zone in Songliao Basin. [R]. Mineral rock, 2017: 66-73. 